$$
\text { "tmcs-nguyen" — 2012/11/25 — 14:16 — page } 299 \text { — \#1 }
$$

\title{
A differentiated e-learning teaching program in mathematics
}

\author{
Nam Nguyen-Danh and Trung Tran
}

\begin{abstract}
The intelligent online interactions between students and teacher are still not assured because of the fact that a learning management system could not play the role of a teacher in producing a chain of deduction. Furthermore, managing a course in existing e-learning systems has not yet guaranteed the differentiated teaching because it does not enable students to appropriately learn at their corresponding levels. In this paper, we would like to introduce a differentiated e-learning course in Vietnam. We also present some designing principles for such courses and propose some typical situations in teaching mathematics aimed at helping high school students individualize their online learning in mathematics.
\end{abstract}

Key words and phrases: e-learning, online learning, differentiated teaching, decision support system, deduction chain.

ZDM Subject Classification: D40, Q60, U50, U70.

\section{Introduction}

The existing e-learning systems have deficiencies in providing personalized preferences because they provide different students, who have their own interest and characteristics, with the same resources (Chen, Fang and Zhao, 2012). Similarly, the e-learning systems in Vietnam are often designed in a linear program for all students. The teaching diagram of a lesson in such online courses can be represented in the form of units of knowledge (UK) as follows:

Copyright (C) 2012 by University of Debrecen 


$$
\text { "tmcs-nguyen" — 2012/11/25 — 14:16 — page } 300 \text { — \#2 }
$$

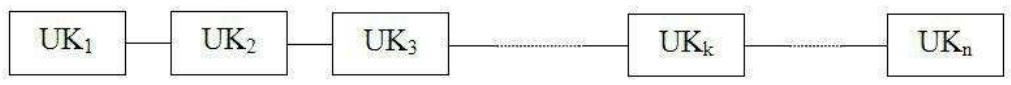

Figure 1. A linear program for an online course

According to this diagram, the total knowledge of a lesson is divided into a sequence of "smaller UK". This lesson is organized in a way that enables students to pass through each UK step by step. The students would be inculcated upon the content of the lesson if they can overcome all of these steps. It is obvious that this approach does not meet requirements of the differentiated teaching. Consequently, many students may find this teaching approach quite boring, especially the students who have high levels of current knowledge. These students may not be interested in such linear program teaching. Therefore, it is essential for teachers to design a differentiated e-learning teaching program which guarantee individual effective learning needs for students, who also have different learning styles. This also means that the program should be suitable to students' learning paces and offer the optimal learning path for each student (Kozierkiewicz-Hetmanska, 2009). On the basis of these recommendations, we designed an online course with a differentiation program aimed at providing mathematics students with an opportunity to develop their flexible thinking and creativity in solving problems.

\section{Principles for designing a differentiated e-learning teaching program}

An effective and quality learning requires an employment of appropriate learning theory and paradigms, organization of contents, as well as methods and techniques of delivery (Sun, Williams and Liu, 2005; Kozierkiewicz-Hetmanska, 2009). Therefore, in this research, we concentrated on some designing principles for a differentiated e-learning teaching program, especially some typical teaching situations. In order to verify these principles, we created a website http://www.toan12. net with a differentiated e-learning teaching program for high school mathematics students in Vietnam. This program created learning environment preferable by student and offered the best learning path for an individual. It also allowed teachers to modify learning path during learning process 


$$
\text { "tmcs-nguyen" — 2012/11/25 - 14:16 — page 301 — \#3 }
$$

as well as analyze student's mistakes based on collected data. The principles for designing such program are presented as follows:

(1) Content knowledge principle. With the purpose of individualizing students' learning styles, the content knowledge should be divided into a sequence of differentiated lessons with different learning strategies. Each lesson takes responsibility for a specific type of content knowledge.

(2) Teaching strategy principle. Making appropriately teaching strategies for each lesson and determining sequences of UK. The time for self-studying in each UK should last from 10 to 20 minutes depending on students' levels of current knowledge. In particular, the content of each UK should contain a concept, a property, a theorem, or a mathematical structure. We will present the ways the teachers teach these contents in the next section, which are called typical teaching situations in mathematics.

(3) Learning style principle. Determining the students' backgrounds and individually learning styles based on tests, questionnaire, regular observations, and personal interviews. Then teachers sketch a differentiated teaching diagram for each UK by using multiple-choice questions. The program will suggest to students to produce an appropriately deductive chain of reasoning corresponding to their choice of responses. With students' different learning styles, the program should also provide different teaching strategies to maximize the individual learning process as well as collect instant feedback from students. For example, the following diagram shows the differentiated teaching program for students' responses in a question. The program provided students with an appropriate suggestion corresponding to their choices:

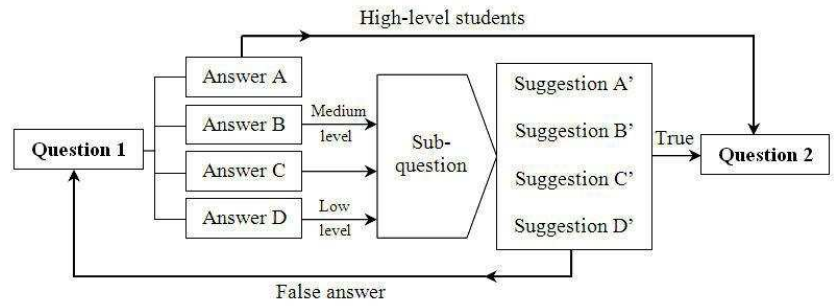

Figure 2. for differentiated e-learning teaching program

During the period of experimental teaching in Vietnam, we realized that each student has her/his own path of learning with different learning paces. These principles also make a contribution to improve the quality of designing online courses 


$$
\text { "tmcs-nguyen" — 2012/11/25 — 14:16 — page } 302 \text { — \#4 }
$$

with a differentiated teaching program. However, teachers should flexibly apply the principles to typical teaching situations aimed at creating more meaningful activities for students in such courses.

\section{Typical teaching situations in mathematics}

\subsection{Teaching mathematical concept}

Mathematical concepts play an important role in understanding the content knowledge in mathematics. They are also used to classify some mathematical structures. Therefore, teaching a concept is the most important task for teachers both in a traditional classroom and an online course. In this research, a mathematical concept in the differentiated program was taught based on the following stages:

Firstly, the differentiated teaching program should propose an unresolved problem in order to create an indispensable situation for forming the concept. Students analyze the situation and interact with the objects in a 'new situation'. This situation takes a responsibility for motivating students to solve the given problem. For instance, the program asks students to determine common characteristics of the objects which related to the concept. Then it may guide students to generalize about the concept definition. In particular, teachers should anticipate the differentiation in students' levels before designing the program in this stage. Some high level students can recognize immediately these typical characteristics of the given objects, whereas the others may not aware of these signals and even make some mistakes. Therefore, the program should provide each student supplementary tasks to generalize about the concept using recognized typical characteristics. The following diagram describes the process of teaching a mathematical concept:

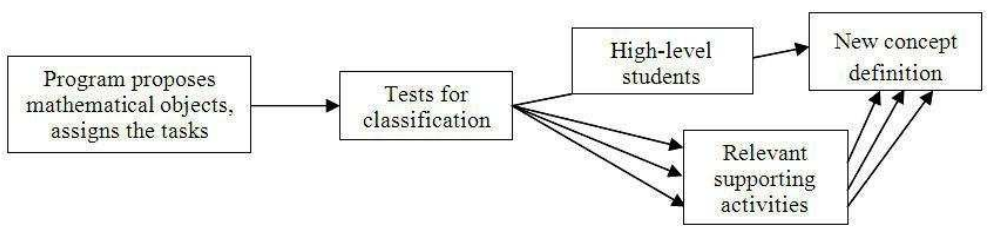

Figure 3. A differentiated teaching program of a mathematical concept
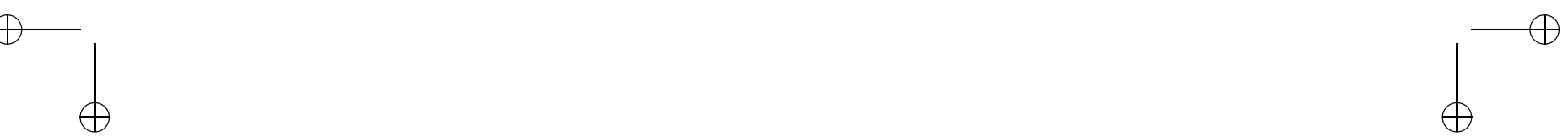


$$
\text { "tmcs-nguyen" — 2012/11/25 — 14:16 — page } 303 \text { — \#5 }
$$

Secondly, the program should offer students exercises for consolidation. A suitable exercise should be given aimed at applying the perceived concept. There are two typical types of the exercises: identifying the concept and expressing the concept. For instance, the program provides low level students with tasks of identifying and expressing concepts in simple situations, while it provides medium level and high level students with tasks in more complex situations. An exercise of identifying a mathematical concept is organized as follows:

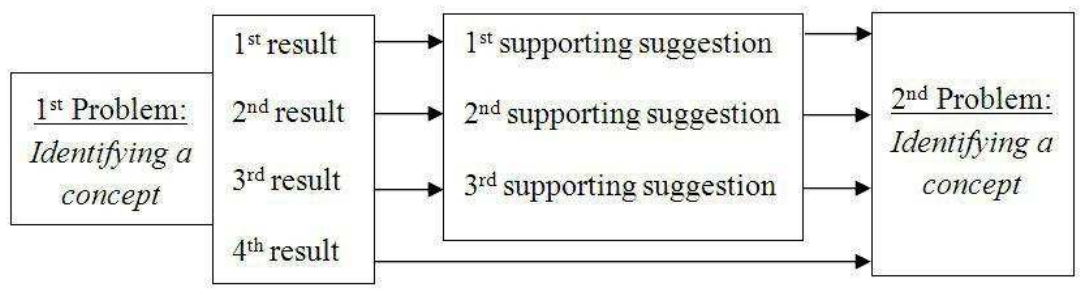

Figure 4. A differentiated teaching program of identifying a mathematical concept

\subsection{Teaching mathematical property and mathematical theorem}

Mathematical properties and theorems are taught in a high school with the aims of understanding mathematical concepts, consolidating content knowledge, and developing mathematical thinking. In this research, a property or a theorem is introduced and constructed by the following stages:

Firstly, the program should guide students to explore new property and theorem on their own by analyzing typical properties of mathematical objects, examining the relationship between them, and inferring new theorem by using a chain of logical deduction.

Secondly, the program should instruct and motivate students to prove mathematical properties or theorems. This process requires a chain of logical deduction from a supposition to a conclusion. Normally, a proof of theorem contains from three to four steps of using deduction that help students find out a certain property (or a theorem). This property is called intermediary conclusion (IC). The following linear diagram is representing a "deduction key" for teaching a mathematical property or theorem: 


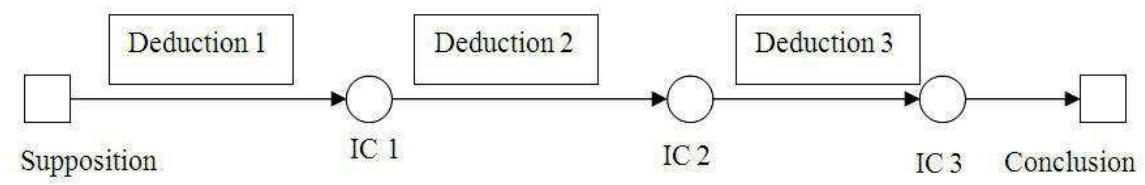

Figure 5. A differentiated e-learning teaching program of a property or theorem

In aforementioned chain of logical deduction, high level students might not have difficulty in transition from one deduction step to another while low level students require some supplementary supports. In this teaching situation, the differentiated e-learning program takes responsibility for determining suitable teaching methods and strategies in order to help students 'overcome' these deduction keys. For instance, some students smoothly passage from the $\mathrm{IC}_{k-1}$ to $\mathrm{IC}_{k}$ by using deduction $k-1$ but the others might need some supported tasks in order to obtain the same conclusion $\mathrm{IC}_{k}$ :

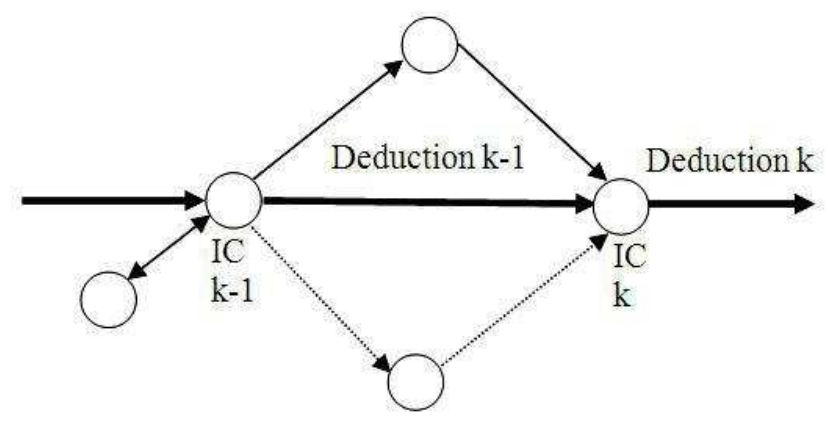

Figure 6. A deduction key in differentiated e-learning teaching program

Thirdly, the program should guide students to apply mathematical properties or theorems to other contexts. This activity can be feasibly implemented by tackling some practical problems. However, the process of finding the answer for questions or exercises needs to be differentiated so that it can individualize students' learning process. For example, the following diagram describes different students' paths of solving a problem, i.e. the ways from the question (Q) to the answer (A). Five students (Tân, Phuong, Liêm, Thanh, and Mai) have different paths of finding the solution of the problem. 


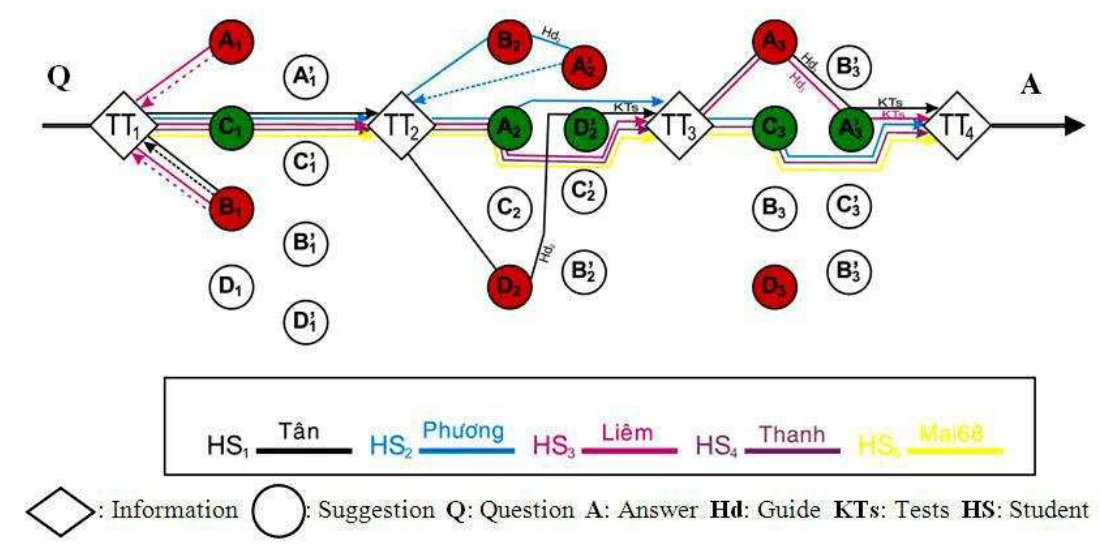

Figure \%. The different paths of finding the answer

Low level students had complex long paths during the learning process. Therefore, the differentiated program should provide these students with more information and suggestions at some points where they meet difficulties. In order to determine these obstacles, the program should offer some tests, collect data from each student, and then automatically sketch a suitable path for each student as a decision support system in the individual learning process.

\section{Building a decision support system}

A decision support system should be built for the differentiated e-learning teaching program because it provides students with an intelligent intervention and support them in making their decisions on the right track. In this research, the support system was divided into UK by the following tasks: introducing basic content knowledge, posing questions, receiving students' responses, examining students' solutions, and providing feedback for students' responses.

This system must consider whenever students go on to the next UK. Therefore, in order to build an effective decision support system, we must apply the following stages: understanding, designing, selecting, and installing (Turban and Aronson, 1998). Making decision in a teaching process is a sequence of decisions such as which questions, for whom, at which position of the logical diagram of subject, and why. Generally speaking, a decision support system could not give the final decision itself. It supports students to learn with suitable paths and 


$$
\text { "tmcs-nguyen" — 2012/11/25 — 14:16 — page } 306 \text { — \#8 }
$$

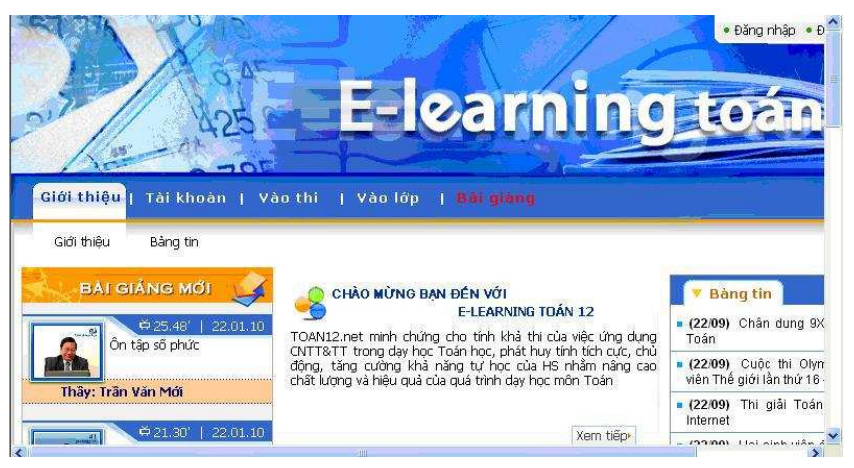

Figure 8. A differentiated e-learning program at the http://www.toan12.net

also supports teachers to consider an appropriate teaching methods and strategies. Therefore, a decision support system should be constructed in the following stages: modeling students' perception of teaching contents, establishing a mechanism for anticipating level of students at different periods of time, making suitable pedagogical decision during the teaching process. It also should analyze student's solutions in order to provide decision of the next UK based on student's corresponding level. In order to design an effective system, the following technical models should be used:

- Basing on the change of pedagogical strategies about a certain teaching problem, teachers can scrutinize students' responses to suggest a method of expressing students' mistakes, then find out a common rule for all these mistakes. However, it is difficult for the program to automatically anticipate students' knowledge background. Therefore, it is only possible to consider the initial and expected students' knowledge and abilities.

- Using graph theory to draw a diagram of students' thinking, reasoning, and problem-solving skills and embed this diagram into teachers' deduction structure. Intelligent e-learning systems should provide direct and customized instructions to students without human intervention. Therefore, it should be accurately planned to offer a suitable learning path for students' knowledge background and adapt learning materials to student's preferences, learning styles, interests, and abilities in each step of the learning process (see e.g. Kozierkiewicz-Hetmanska and Nguyen, 2010).

- Building a semantic network containing some branches that are corresponding to appropriate teaching situations and students' knowledge background. 


$$
\text { "tmcs-nguyen" — 2012/11/25 — 14:16 — page } 307 \text { — \#9 }
$$

To sum up, on the basis of students' personalized characteristics, the differentiated teaching program should be attached a decision support system in order to individualize student's path of learning. This system also helps students minimize their study time as well as overcome some cognitive and technical difficulties during the process of online learning.

In our differentiated e-learning teaching program, a decision support provided students with a suitable content knowledge and learning strategy. It also collected some personal materials about each student and suggested teachers to analyze students' feedbacks. As a result, teachers designed new teaching diagram and chose an appropriate teaching method for each student.

\section{Conclusion}

In summary, with the purpose of differentiating students' learning process, we designed a differentiated teaching program and built an online course for high school mathematics students in Vietnam. This course makes a contribution to individualize students' learning by using a decision support system. The teaching program provides students with the appropriate UK and learning path corresponding to their levels. In this research, we have proposed some designing principles and typical teaching situations for such programs with the aim of maximizing students' learning performance both in traditional and online courses. It is also easier for teachers to assess and classify students' level of understanding based on this program by analyzing feedbacks from students. The program also suggests teachers to choose appropriate content knowledge and teaching strategies as their perfect way of teaching. This means that each student has her/his own path and pace of learning based on individual backgrounds, preferences, interests, learning styles, and abilities. Therefore, a differentiated teaching program would make a contribution to improve students' learning outcomes in such online courses.

\section{References}

[1] Z. Chen, L. Fang and T. Zhao, The application of semantic web in e-learning personalized knowledge query, in: Software Engineering and Knowledge Engineering, Vol. 2, (Y. Wu, ed.), Springer-Verlag, Berlin, 2012, 881-885.

[2] J. Durkin, Expert system design and development, Prentice Hall, New Jersey, 1994. 


$$
\text { "tmcs-nguyen" — 2012/11/25 — 14:16 — page } 308 \text { - \#10 }
$$

[3] A. Kozierkiewicz-Hetmanska, A conception for modification of learning scenario in an intelligent e-learning system, Lecture Notes in Computer Science, Springer-Verlag, Berlin (2009), 87-96.

[4] A. Kozierkiewicz-Hetmanska and N. T. Nguyen, A method for scenario modification in intelligent e-learning systems using graph-based structure of knowledge, in: Studies in computational intelligence, (N. T. Nguyen, ed.), Springer-Verlag, Berlin, 2010, 169-179.

[5] A. Newell and H. Simon, Human problem solving, Prentice Hall, New Jersey, 1973.

[6] L. Sun, S. Williams and K. Liu, Knowledge construction in e-learning designing an e-learning environment, in: Enterprise information systems, Vol. V, (O. Camp et al, eds.), Kluwer Academic Publishers, Netherlands, 2005, 308-315.

[7] E. Turban and J. Aronson, Decision support systems and intelligent systems, Prentice Hall, New Jersey, 1998.

NAM NGUYEN-DANH

UNIVERSITY OF WÜRZBURG

GERMANY

E-mail: danh-nam.nguyen@mathematik.uni-wuerzburg.de

TRUNG TRAN

SAM SON ETHNIC PRE-UNIVERSITY

VIETNAM

E-mail: trungt.dbdhss@moet.edu.vn

(Received September, 2011) 